УДК 548.0:534+004.942

\title{
Features of the Metallization Influence on Phase Velocities of Acoustic Waves in Piezoelectric Plates
}

\author{
Olga P. Zolotova* \\ Reshetnev Siberian State University of Science and Technology \\ Krasnoyarskiy Rabochiy, 31, Krasnoyarsk, 660037 \\ Russia \\ Sergey I. Burkov ${ }^{\dagger}$ \\ Institute of Engineering Physics and Radio Electronics \\ Siberian Federal University \\ Svobodny, 79, Krasnoyarsk, 660041 \\ Russia
}

Received 08.05.2019, received in revised form 17.07.2019, accepted 25.09.2019

The paper presents an analysis of the influence of the load represented by two metal layers on the change in the phase velocity of the dispersion modes of the elastic Lamb and $\mathrm{SH}$-waves in "Me/ZnO/Me" and "Me/AlN/Me" structures depending on the elastic wave frequency and the ratio of the metal layer to the piezoelectric layer thickness. Aluminum (Al), molybdenum (Mo) and platinum (Pt) are considered as the metal layer materials (Me). Only the elastic Lamb wave modes have localized maxima of the sensitivity curve $S$ for all types of structures. Systems with low values of acoustic impedances for layers and plates materials have maximum values of $S$ for metallization with thin layers, and also have minimal differences in the profiles of the components of the displacement vectors of the elastic wave. Systems with the most different values of acoustic impedances of layers and plates materials have maximum values of $S$ when metallized with thick layers, and also have maximum differences in the profiles of the components of the displacement vectors of the elastic wave.

PACS: 43.25.Fe; 43.35. Cg; 77.65.-j

Keywords: piezoelectric plate, Lamb wave, SH-wave, mass loading, computer simulation. DOI: $10.17516 / 1997-1397-2019-12-6-718-727$.

\section{Introduction}

Acoustic Lamb waves in piezoelectric plates are a promising object for the development of microwave resonators and sensors of the next generation. Due to the high interest in this issue, many experimental and theoretical studies of acoustoelectronic devices based on piezoelectric plates operating on various modes of elastic waves have appeared $[1,2]$.

In devices created on the basis of a single-layer or multilayer piezoelectric structure, the thickness of the electrodes can be comparable to the thickness of the piezoelectric plate. At the same time, precious metals such as gold or platinum, which are most often used in sensors for various biochemical applications, have significant values of acoustic impedance [3]. Thus, taking into account the influence of metal layers on the change in the dispersion characteristics of various

\footnotetext{
*zolotova@sibsau.ru

†sburkov@sfu-kras.ru

(c) Siberian Federal University. All rights reserved
} 
modes of an elastic wave in a piezoelectric plate is important for improving the characteristics of devices on such structures [4].

In this paper, we performed a computer simulation of two thin metal layers influence on the dispersion characteristics of the elastic Lamb wave modes in zinc oxide ("Me/ZnO/Me" structures) and aluminum nitride ("Me/AlN/Me" structures) plates. These piezoelectrics have large values of the electromechanical coupling coefficient and significant values of the phase velocities of bulk and surface acoustic waves. Due to these properties, the materials in question are actively used in the development of various acoustoelectronic devices. As materials of metal layers $(\mathrm{Me})$, aluminum $(\mathrm{Al})$, molybdenum $(\mathrm{Mo})$ and platinum $(\mathrm{Pt})$ were used in the form of a sputtered thin film, that are metals often used as electrodes [5]. All materials used for layers and plates modeling have different values of acoustic impedance $Z=\rho v$, calculated for bulk longitudinal wave, which are related as $Z_{\mathrm{Al}}<Z_{\mathrm{AlN}}<Z_{\mathrm{ZnO}}<Z_{\mathrm{Mo}}<Z_{\mathrm{Pt}}$. The values of material constants for aluminum and molybdenum are taken in [5], $\mathrm{ZnO}-$ in [6], AlN - in [7], platinum - in [8].

\section{Theoretical foundations for elastic waves propagation in a layered piezoelectric medium}

The equation of motion, the equation of electrostatics, and the equations of state of the piezoelectric medium, describing the propagation of an elastic wave in a piezoelectric, have the form of $[9]$

$$
\begin{gathered}
\rho_{0} \ddot{\mathbf{U}}_{A}=\tau_{A B, B}, \quad \mathbf{D}_{M, M}=0, \\
\tau_{A B}=c_{A B C D}^{E} \eta_{C D}-e_{M A B} E_{M}, \quad \mathbf{D}_{M}=\varepsilon_{M N}^{\eta} E_{N}+e_{M A B} \eta_{A B},
\end{gathered}
$$

where $\rho_{0}$ is the crystal density in undeformed state; $\mathbf{U}_{A}$ is the vector of dynamic elastic displacements; $\tau_{A B}$ is the thermodynamic stress tensor; $\mathbf{D}_{M}$ is the vector of electrical induction; $\eta_{C D}$ is the small strain tensor; $c_{A B C D}^{E}, e_{M A B}, \varepsilon_{M N}^{\eta}$ - elastic, piezoelectric and dielectric constants of the second order. The comma after the index denotes the spatial derivative, the Latin coordinate indices vary from 1 to 3 . Hereinafter implies the summation of the twice-repeated index.

In a working orthogonal system of axis, the $X_{3}$ axis is directed along the outer normal to the layer surface and $X_{1}$ axis coincides with the direction of wave propagation (Fig. 1,a). The boundary conditions, in particular, for the "Me/Piezoelectric/Me" three-layer structure are: the equality to zero of normal components of the stress tensor at the "metal/vacuum" interface; the normal components equality of the stress tensor, the equality of the displacement vectors and the equality to zero of the electric potential wave at the "metal/piezoelectric" interface [10]:

$$
\begin{aligned}
& \left.\tau_{3 j}^{(1)}\right|_{x_{3}=d_{1}}=0, \\
& \tau_{3 j}^{(1)}=\left.\tau_{3 j}^{(2)}\right|_{x_{3}=h}, \quad \varphi^{(2)}=\left.0\right|_{x_{3}=h}, \quad \overrightarrow{\mathbf{U}}^{(1)}=\left.\overrightarrow{\mathbf{U}}^{(2)}\right|_{x_{3}=h}, \\
& \tau_{3 j}^{(2)}=\left.\tau_{3 j}^{(3)}\right|_{x_{3}=d_{2}}, \quad \varphi^{(2)}=\left.0\right|_{x_{3}=d_{2}}, \quad \overrightarrow{\mathbf{U}}^{(2)}=\left.\overrightarrow{\mathbf{U}}^{(3)}\right|_{x_{3}=d_{2}}, \\
& \left.\tau_{3 j}^{(3)}\right|_{x_{3}=0}=0 .
\end{aligned}
$$

Here $d_{1}, d_{2}$ and $h$ are the thicknesses of the upper and lower metal layer and piezoelectric layer, respectively. In the present paper, the condition $d_{1}=d_{2}$ is met, i.e. the thickness of the upper and lower metal layers are equal. The equality to zero of the boundary conditions 
determinant matrix (2), which size in this case is $20 \times 20$ elements, makes it possible to calculate the phase velocities of symmetric and antisymmetric modes of the Lamb and $S H$-wave. Boundary conditions variations (2) determine all types of elastic waves propagating in the three-layer plate.

\section{Analysis of the loading on the wave velocities in three-layer plates}

There are several determinations of the sensitivity parameter in the piezoelectric structure to a mass loading $[11,12]$. In particular, the mass sensitivity $S$ of a multilayer resonator can be defined as a relative frequency shift of the resonator, normalized to the surface mass density [12]. However, the disadvantage of this approach is that for large values of $f$ frequencies, the changes of phase velocity are smoothed in case of increase in the metal layer thickness.

In the present work, the following formula to determine the mass sensitivity of an elastic wave is used:

$$
S=\frac{1}{D \rho_{0}}\left(\frac{\Delta v}{v}\right),
$$

where $\Delta v=v-v_{m e t}$ is the change in the phase velocity of the elastic wave during the deposition of a metal layer with bulk density $\rho_{0}, D$ is the total thickness of the metal layers. The velocity shift is calculated relative to the velocity of the elastic wave when an infinitely thin layer is applied, which does not change the mechanical boundary conditions [13,14]. Note that as shown by the computer experiment, this condition is fulfilled at a layer thickness of less than $1 \mathrm{~nm}$. Also, condition (3), eliminates the effect of the piezoelectric effect and, therefore, $S$ parameter doesn't depend on the type of the piezoelectric layer.

A schematic representation of the investigated layered structures is presented in Fig. 1, a. The dispersion dependences of phase velocities for the fundamental and first modes of Lamb and $S H$ waves on parameter $u=h \cdot f$ value (the product of the piezoelectric thickness and frequency) for the $\mathrm{Al} / \mathrm{ZnO} / \mathrm{Al}$ " layered structure with the $[100](001)$ layer orientation is presented in Fig. 1, b, similar dependences for the " $\mathrm{Al} / \mathrm{AlN} / \mathrm{Al}$ " layered structure with the [100] (001) layer orientation are shown in Fig. 1, c. In contrast to the "Me/ZnO/Me" structure with the maximum value of $u$ $=10000 \mathrm{~m} / \mathrm{s}$, the range of variation of the parameter $u$ to $20000 \mathrm{~m} / \mathrm{s}$ was increased to calculate the second structure due to the fact that the values of the phase velocities of all elastic wave modes become much larger.

The phase velocities of zero modes of the elastic Lamb wave in the "Me/ZnO/Me" structure during metallization with infinitely thin layers tend to the phase velocity of the Rayleigh wave in $\mathrm{ZnO}$ with metallized surfaces $(v=2677.6 \mathrm{~m} / \mathrm{s})$. In the "Me/AlN $/ \mathrm{Me}$ structure the phase velocities of the traveling modes of an elastic wave change in the same way and tend to the Rayleigh wave phase velocity in AlN with metallized surfaces $(v=5485 \mathrm{~m} / \mathrm{s})$. The speeds of higher-order traveling modes of the Lamb wave with increasing $u$ parameter decrease from several tens of $\mathrm{km} / \mathrm{s}$ and tend to the speed of a slow shear bulk wave in a piezoelectric. The phase velocities of all the $S H$-wave modes tend to the speed of a fast shear bulk wave in a piezoelectric.

The use of metal in a multilayer plate can significantly affect the redistribution of the elastic wave energy due to the acoustic properties of the layers, as well as the interference between the incident and reflected elastic wave modes from the layer boundaries. For example, in the "Al/AlN/Al" structure the increasing $u$ parameter and using of maximum thickness metal layers $(d / h=0.05)$, the phase velocities of the elastic wave fundamental modes decrease significantly and tend to the value of the phase velocity of the fast shear wave in aluminum (Fig. 1, c). A 
similar situation manifests itself when using other considered metals in the multilayer structure. It is noted that in the "Me/AlN/Me" structure the velocities of the elastic wave modes with the same metal type and $u$ value decrease more significantly than in the "Me/ZnO/Me" structure.

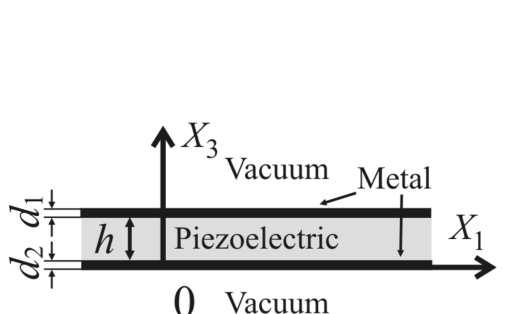

$a$

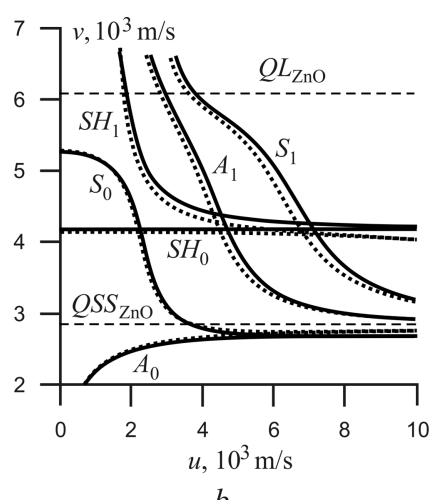

$b$

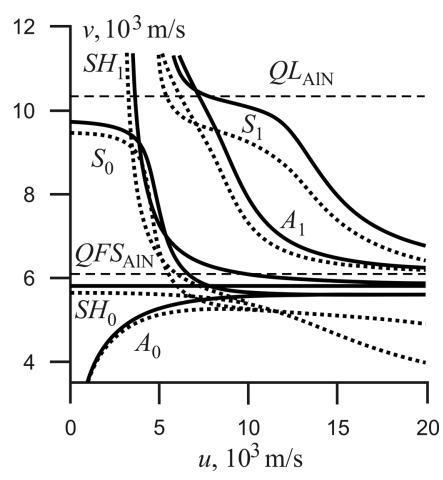

$c$

Fig. 1. Dispersion dependences of phase velocities on $u$ parameter for the "Al/Piezoelectric/Al" layered structure: $a$ - the layered structure scheme; $b$ - fundamental and first Lamb and $S H$ wave modes in the "Al/ZnO/Al" structure; $c$ - the fundamental and first Lamb and $S H$-wave modes in the "Al/AlN/Al" structure. Solid lines - the mode velocities for infinitely thin metal layers, dotted lines - the velocities for the metal and layer ratio $d / h=0.05$

Fig. 2 represents the graphs of sensitivity $S$ calculated by the formula (3) for the fundamental modes $A_{0}, S_{0}$, the first modes $A_{1}, S_{1}$ of the Lamb wave, and also the fundamental and two first modes of the $S H$-wave, depending on the parameter $u$ in the "Al/ZnO/Al" (Fig. 2, $a$ ) and "Al/AlN/Al" (Fig. 2, b) structures with the $d / h$ ratio $=0.001$.

It can be noted that the all modes of the elastic Lamb wave (except $A_{0}$ mode) have sensitivity $S$ maxima that appear at almost equal intervals of the parameter $u$ values.
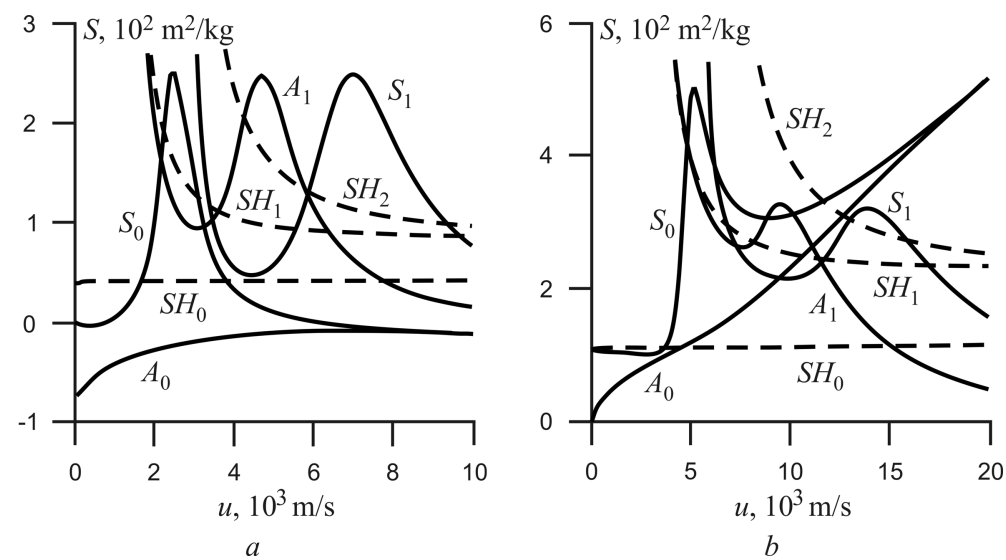

Fig. 2. Dispersion dependences of the sensitivity $S$ of the elastic Lamb and $S H$-wave modes on the parameter $u$ with the ratio of the thicknesses of the metal and piezoelectric $d / h=0.001$ : $a-" \mathrm{Al} / \mathrm{ZnO} / \mathrm{Al} "$ structure; $b-" \mathrm{Al} / \mathrm{AlN} / \mathrm{Al} "$ structure

It is noted that the maximum values of $S$ in the " $\mathrm{Al} / \mathrm{AlN} / \mathrm{Al}$ " structure exceed the similar values for the same modes of the elastic Lamb wave by two times. At the same time, the acoustic 
impedances of the bulk longitudinal wave for the piezoelectric layer are not so different and equal for $Z_{\mathrm{AlN}}=3.35 \cdot 10^{7} \mathrm{~kg} \cdot \mathrm{m} / \mathrm{s}^{2}$ and $Z_{\mathrm{ZnO}}=3.45 \cdot 10^{7} \mathrm{~kg} \cdot \mathrm{m} / \mathrm{s}^{2}$.

The sensitivity graphs of $S$ for the fundamental antisymmetric wave mode $A_{0}$ and $S H$-modes with transverse-horizontal polarization on the studied frequency range have no features. It can be noted that a decrease (in absolute value) of $S$ in the " $\mathrm{Al} / \mathrm{ZnO} / \mathrm{Al}$ " structure is associated with a gradual increase of $A_{0}$ mode speed with an increase in the $u$ parameter values (Fig. 2, a). On the contrary, the increase of $S$ values in the "Al/AlN/Al" structure is associated with a significant drop in $A_{0}$ mode speed with an increase in the $u$ parameter values (Fig. 2, b). The decrease in $S$ values for modes with transverse-horizontal polarization is associated with a gradual decrease in the velocities of these modes when increasing the parameter $u$ values. In the following, only features of the behavior of sensitivity curves $S$ for the elastic Lamb wave modes are considered.

Next, we calculated the phase velocities change for the modes of the elastic wave with the ratio of one metal layer to the piezoelectric thickness $d / h=0.005 ; 0.01 ; 0.025 ; 0.05$. The maximum sensitivity values for the $S_{0}, A_{1}$ and $S_{1}$ modes of Lamb wave depending on the type of metal layer, the $d / h$ ratio and the $u$ value in the "Me/ZnO/Me" structure are shown in Tab. 1 .

A significant decrease in the maximum sensitivity $S$ for the elastic wave modes considerated appears at a ratio $d / h>0.025$. This decrease in $S$ values with increasing $d / h$ is especially evident when using $\mathrm{Pt}-$ a metal with a high acoustic impedance value. The numerical values of the $S$ maxima for all types of metal differ only with significant layer thicknesses (Tab. 1).

Table 1. Maximum values of sensitivity $S$ in the structure "Me/ZnO/Me"

\begin{tabular}{|c|c|c|c|c|c|c|c|c|c|c|}
\hline \multirow[t]{2}{*}{$d / h$} & Mode & \multicolumn{3}{|c|}{$S_{0}$} & \multicolumn{3}{|c|}{$A_{1}$} & \multicolumn{3}{|c|}{$S_{1}$} \\
\hline & Metall & Al & Mo & $\mathbf{P t}$ & Al & Mo & $\mathbf{P t}$ & Al & Mo & $\mathbf{P t}$ \\
\hline \multirow[t]{2}{*}{0.001} & $S, \mathrm{~m}^{2} / \mathrm{kg}$ & 251 & 246 & 275 & 248 & 247 & 248 & 249 & 248 & 246 \\
\hline & $u, \mathrm{~m} / \mathrm{s}$ & 2500 & 2400 & 2500 & 4700 & 4700 & 4700 & 7000 & 7000 & 6900 \\
\hline \multirow[t]{2}{*}{0.005} & $S, \mathrm{~m}^{2} / \mathrm{kg}$ & 248 & 244 & 269 & 246 & 242 & 238 & 248 & 243 & 236 \\
\hline & $u, \mathrm{~m} / \mathrm{s}$ & 2500 & 2400 & 2500 & 4700 & 4700 & 4700 & 7000 & 7000 & 6900 \\
\hline \multirow[t]{2}{*}{0.01} & $S, \mathrm{~m}^{2} / \mathrm{kg}$ & 246 & 240 & 258 & 244 & 237 & 225 & 245 & 237 & 221 \\
\hline & $u, \mathrm{~m} / \mathrm{s}$ & 2400 & 2400 & 2500 & 4700 & 4600 & 4600 & 6900 & 6900 & 6700 \\
\hline \multirow[t]{2}{*}{0.025} & $S, \mathrm{~m}^{2} / \mathrm{kg}$ & 239 & 223 & 226 & 238 & 220 & 188 & 240 & 214 & 189 \\
\hline & $u, \mathrm{~m} / \mathrm{s}$ & 2400 & 2400 & 2400 & 4600 & 4500 & 4300 & 6800 & 6800 & 6000 \\
\hline \multirow[t]{2}{*}{0.05} & $S, \mathrm{~m}^{2} / \mathrm{kg}$ & 225 & 199 & 180 & 228 & 190 & 142 & 233 & 177 & 152 \\
\hline & $u, \mathrm{~m} / \mathrm{s}$ & 2400 & 2300 & 2200 & 4500 & 4400 & 3900 & 6700 & 6500 & 5300 \\
\hline \multicolumn{2}{|c|}{$\begin{array}{c}\text { Mean value of } u \text { in } \\
\text { maximum } S, \mathrm{~m} / \mathrm{s}\end{array}$} & $\begin{array}{l}2440 \pm \\
136\end{array}$ & $\begin{array}{l}2380 \pm \\
284\end{array}$ & $\begin{array}{l}2420 \pm \\
393\end{array}$ & $\begin{array}{l}4640 \pm \\
305\end{array}$ & $\begin{array}{l}4580 \pm \\
786\end{array}$ & $\begin{array}{l}4440 \pm \\
2565\end{array}$ & $\begin{array}{c}6880 \pm \\
1010\end{array}$ & $\begin{array}{c}6840 \pm \\
1070\end{array}$ & $\begin{array}{c}6360 \pm \\
1120\end{array}$ \\
\hline
\end{tabular}

The maximum sensitivity values for the $S_{0}, A_{1}$ and $S_{1}$ modes of Lamb wave depending on the type of metal layer, the $d / h$ ratio and the $u$ value in the "Me/AlN/Me" structure are shown in Tab. 2.

A significant decrease of sensitivity $S$ for the elastic wave modes considerated is manifested when ratio $d / h>0.025$, especially for using Mo and Pt. The numerical values of the $S$ maxima for all types of metals differ only with significant thicknesses of the layers. The maximum values of $S$ parameter for all modes are 1.5-2 times higher than the similar values for the "Me/ZnO/Me" structure.

At the same time in contrast to the "Me/ZnO/Me" structure, for the considered $S_{0}, A_{1}, S_{1}$ modes of the elastic Lamb wave, a significant increase in the $S$ values was observed when using thick Al layers. In this case, the value of $S$ for large values of $u$ parameter can be comparable 
or even exceed the values at the local maximum. A similar effect was found for the $S_{0}$ mode only in the $\mathrm{Pt} / \mathrm{ZnO} / \mathrm{Pt}$ " structure. At the same time, the situation is possible, for example, for mode $A_{1}$, when the maximum sensitivity is noted at the time of the wave, then a local minimum is observed and subsequently the $S$ value becomes practically dispersionless or begins to increase, which corresponds to a decrease in the phase velocity of a particular mode with increasing thickness of the metal layer.

Table 2. Maximum values of sensitivity $S$ in the structure "Me/AlN/Me"

\begin{tabular}{|c|c|c|c|c|c|c|c|c|c|c|}
\hline \multirow[t]{2}{*}{$d / h$} & Mode & \multicolumn{3}{|c|}{$S_{0}$} & \multicolumn{3}{|c|}{$A_{1}$} & \multicolumn{3}{|c|}{$S_{1}$} \\
\hline & Metall & Al & Mo & $\mathbf{P t}$ & Al & Mo & $\mathbf{P t}$ & Al & Mo & $\mathbf{P t}$ \\
\hline \multirow[t]{2}{*}{0.001} & $S, \mathrm{~m}^{2} / \mathrm{kg}$ & 502 & 493 & 532 & 329 & 327 & 326 & 323 & 321 & 319 \\
\hline & $u, \mathrm{~m} / \mathrm{s}$ & 5200 & 5200 & 5200 & 9600 & 9600 & 9600 & 14000 & 13800 & 13800 \\
\hline \multirow[t]{2}{*}{0.005} & $S, \mathrm{~m}^{2} / \mathrm{kg}$ & 500 & 489 & 525 & 327 & 318 & 303 & 321 & 312 & 336 \\
\hline & $u, \mathrm{~m} / \mathrm{s}$ & 5200 & 5000 & 5000 & 9600 & 9400 & 9200 & 13800 & 13600 & 11800 \\
\hline \multirow[t]{2}{*}{0.01} & $S, \mathrm{~m}^{2} / \mathrm{kg}$ & 497 & 479 & 497 & 324 & 306 & - & 319 & 302 & 387 \\
\hline & $u, \mathrm{~m} / \mathrm{s}$ & 5200 & 5000 & 4800 & 9400 & 9200 & - & 13800 & 13400 & 11600 \\
\hline \multirow[t]{2}{*}{0.025} & $S, \mathrm{~m}^{2} / \mathrm{kg}$ & 494 & 433 & 390 & 318 & 270 & - & 319 & 285 & 425 \\
\hline & $u, \mathrm{~m} / \mathrm{s}$ & 5000 & 4800 & 4600 & 9400 & 8800 & - & 13400 & 12400 & 12400 \\
\hline \multirow[t]{2}{*}{0.05} & $S, \mathrm{~m}^{2} / \mathrm{kg}$ & 476 & 349 & 263 & 313 & 229 & 258 & 364 & 264 & 298 \\
\hline & $u, \mathrm{~m} / \mathrm{s}$ & 5000 & 4600 & 4400 & 9000 & 8000 & 7800 & 12000 & 11800 & 11800 \\
\hline \multicolumn{2}{|c|}{$\begin{array}{l}\text { Mean value of } u \text { in } \\
\text { maximum } S, \mathrm{~m} / \mathrm{s}\end{array}$} & $\begin{array}{l}5120 \pm \\
136\end{array}$ & $\begin{array}{l}4920 \pm \\
284\end{array}$ & $\begin{array}{l}4800 \pm \\
393\end{array}$ & $\begin{array}{l}9400 \pm \\
305\end{array}$ & $\begin{array}{l}9000 \pm \\
786\end{array}$ & $\begin{array}{c}8867 \pm \\
2565\end{array}$ & $\begin{array}{l}13400 \pm \\
1010\end{array}$ & $\begin{array}{l}13000 \pm \\
1070\end{array}$ & $\begin{array}{l}12280 \pm \\
1120\end{array}$ \\
\hline
\end{tabular}

In general, the character of $S$ parameter changes in the "Me/AlN/Me" structures is similar to the changes in $S$ in a three-layer "Me/ZnO/Me" plate.

\section{Features of the $S$ sensitivity curves of Lamb and $S H$-waves in the "Me/ZnO/Me" and "Me/AlN/Me" structures}

For both structures the characteristic feature is that only the $S_{0}, A_{1}$ and $S_{1}$ modes of the elastic Lamb wave have localized maxima of $S$ curves. Other modes haven't pronounced features of sensitivity curves on the studied frequency range.

When comparing the same structures with different thickness of metal layers, it have found that increasing the thickness of the metal layer, as a rule, reduces the propagation velocity of the acoustic waves of first and higher orders. An increase in the thickness of the metal layers leads to a shift of the maxima of $S$ values to the low-frequency region. In this case the amplitude and width of the peaks of $S$ with metal thickness increasing for the "Me/ZnO/Me" plate are less dependent on the type of metal and the $u$ parameter than for "Me/AlN/Me" structure.

When comparing various "Me/Piezoelectric/Me" structures, it is noted that the sensitivity values of the Lamb elastic wave modes at $d / h$ ratio $=0.001 ; 0,005 ; 0.01$ differ slightly. A significant decrease in the sensitivity $S$ for these modes at the ratio $d / h>0.025$, especially when using Mo and Pt, may limit the use of metals with high acoustic impedance values and considerable thickness of layers in sensor devices.

A specific feature of the $S_{0}$ elastic wave mode propagation in the "Me/ $\mathrm{ZnO} / \mathrm{Me}$ " layered structure is the occurrence of negative values of the $S$ parameter then using $\mathrm{Al}$ and Mo, i.e., the value of the elastic wave phase velocity when metal layers are applied can increase compared to 
the wave velocity in the unloaded piezoelectric plate (Fig. 2, a). Moreover, in the "Mo/ZnO/Mo" structure, a negative values of the $S$ parameter are present only for metallization by layers of minimum thickness $(d / h=0.001)$, and in the " $\mathrm{Al} / \mathrm{ZnO} / \mathrm{Al}$ " structure, on the contrary, the values of $S$ become negative and further decrease with increasing $d / h$ ratio. This effect is not observed in the "Me/AlN/Me" layered structure for any of the elastic Lamb wave modes.

Fig. 3 shows the components of the elastic displacement vectors $U_{1}$ and $U_{3}$ of modes $S_{0}, A_{1}$ and $S_{1}$ distributed over the depth of a three-layer plate in local maxima of $S$ sensitivity curves.

The profiles of components of the displacement vectors for $S_{0}$ mode are constructed for local maxima of the $S$ curves in the "Me $/ \mathrm{ZnO} / \mathrm{Me} "$ structures at $u=2200-2400 \mathrm{~m} / \mathrm{s}$ (Fig. 3, a) and in the $" \mathrm{Me} / \mathrm{AlN} / \mathrm{Me}$ structures at $u=4400-5000 \mathrm{~m} / \mathrm{s}$ (Fig. $3, b$ ). It was noted that in general, the nature of the profiles in both structures is the same, and the differences lie in the initial phases of oscillations. The elastic oscillations of $S_{0}$ mode occur in the piezoelectric thickness, and the deformation in metal layers is insignificant. The components $U_{1}$ and $U_{3}$ have a maximum amplitude in both structures when using Al layers. In this case, the components of the displacements using Mo and $\mathrm{Pt}$ are of the same order of magnitude, and their amplitude is approximately 5 times smaller than when using $\mathrm{Al}$.

The profiles of components of the displacement vectors for $A_{1}$ mode are constructed for the local maxima of the $S$ curves in the "Me/ZnO/Me" structures at $u=3900-4500 \mathrm{~m} / \mathrm{s}$ (Fig. 3, c) and in the "Me/AlN/Me" structures at $u=7800-9000 \mathrm{~m} / \mathrm{s}$ (Fig. 3, d). It was also noted that the profiles of the elastic displacement vectors in both structures are similar and the elastic vibrations occur mainly in the thickness of the piezoelectric. But differences were found from the previous mode in the various metals influence on the amplitude of oscillations. The components $U_{1}$ and $U_{3}$ have the maximum amplitude in the "Me/ $\mathrm{ZnO} / \mathrm{Me}$ " structures using $\mathrm{Al}$ and $\mathrm{Pt}$ layers (Fig. 3, c). In contrast, in the "Me/AlN/Me" structures, the components $U_{1}$ and $U_{3}$ have the maximum amplitude when using Mo layers, and then, in descending order, $\mathrm{Al}$ and $\mathrm{Pt}$ (Fig. 3, $d$ ). In addition, when using $\mathrm{Pt}$, both components of the oscillations rapidly decay by as much as a quarter of the piezoelectric layer thickness.

The profiles of components of the displacement vectors for $S_{1}$ mode are constructed for local maxima of $S$ curves in the "Me $/ \mathrm{ZnO} / \mathrm{Me}$ " structures at $u=5300-6700 \mathrm{~m} / \mathrm{s}($ Fig. $3, e)$ and in the "Me/AlN/Me" structures at $u=11800-12000 \mathrm{~m} / \mathrm{s}$ (Fig. 3, f). The profiles of the vectors of elastic displacements in both structures already differ significantly. The components $U_{1}$ and $U_{3}$ have the maximum amplitude in the "Me/ $\mathrm{ZnO} / \mathrm{Me}$ " structures when using Pt layers, while the minimum displacements are observed with $\mathrm{Al}$ and $\mathrm{Mo}$, i.e. the picture of displacements is opposite to the observed picture for the $S_{0}$ mode (Fig. 3, a). On the contrary, in the "Me/AlN/Me" structures, the $U_{1}$ and $U_{3}$ components have the maximum amplitude when using $\mathrm{Al}$ and $\mathrm{Mo}$ layers, and when using $\mathrm{Pt}$, the oscillation amplitude decreases by 3 orders of magnitude, and both components quickly decay by a quarter of the thickness of the piezoelectric layer $\left(U_{1}\right.$ and $U_{3}$ for $\mathrm{Pt}$ are not shown in Fig. 3, f). In addition, in these structures elastic oscillations occur both in the metal layers and in the thickness of the plate with a sharp change of amplitude and phase at the metal-piezoelectric boundary, especially for the $U_{1}$ component for all types of metals.

It is also noted that the minimal differences in the profiles of the elastic wave displacement vectors are achieved for the $S_{0}$ mode and for "Al/Piezoelectric/Al" configuration of layered system, i.e. in the systems with low acoustic impedances of the layers and piezoelectric materials. The maximum differences in these profiles are achieved for the $S_{1}$ mode and for "Pt/Piezoelectric/Pt" configuration of layered system, i.e. in systems with the most different values of materials acoustic impedances. 


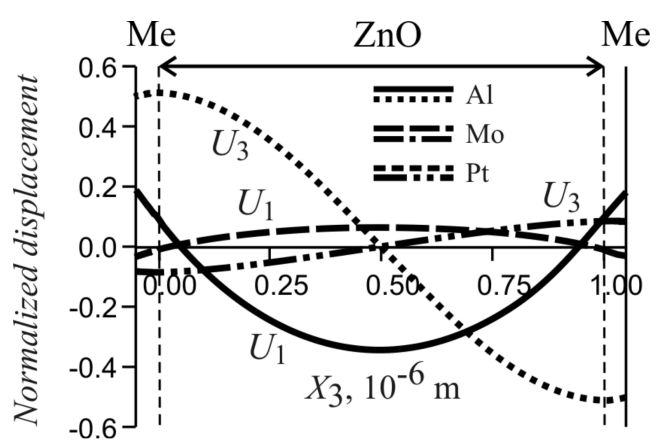

$a$

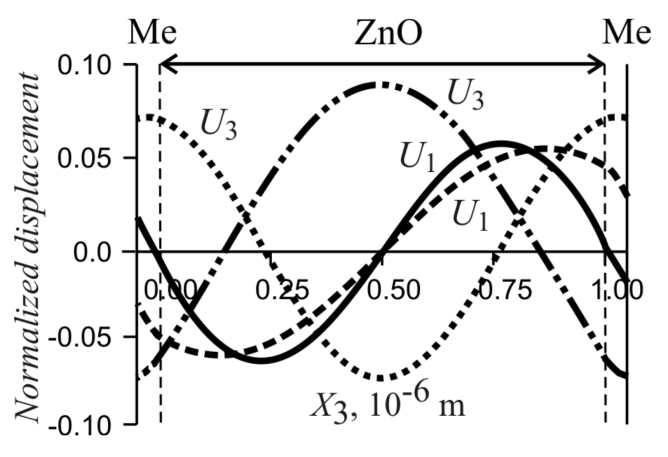

c

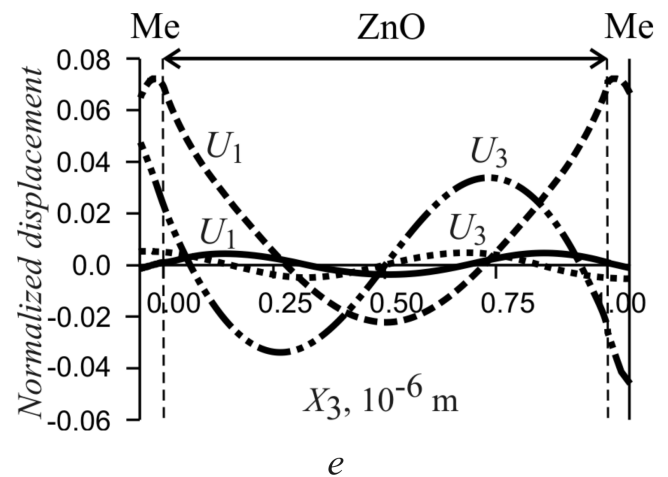

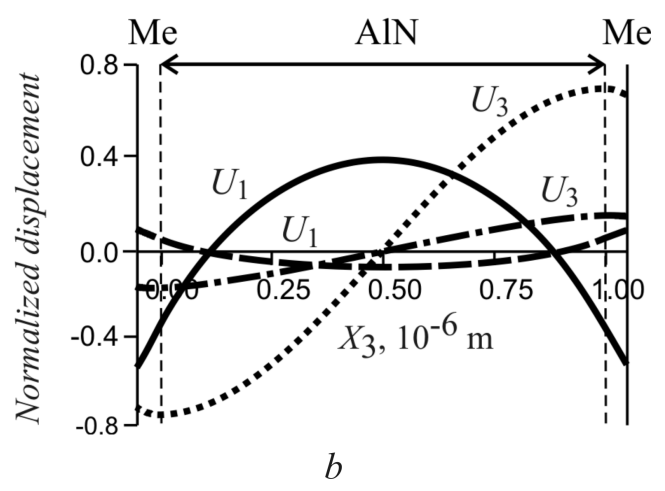
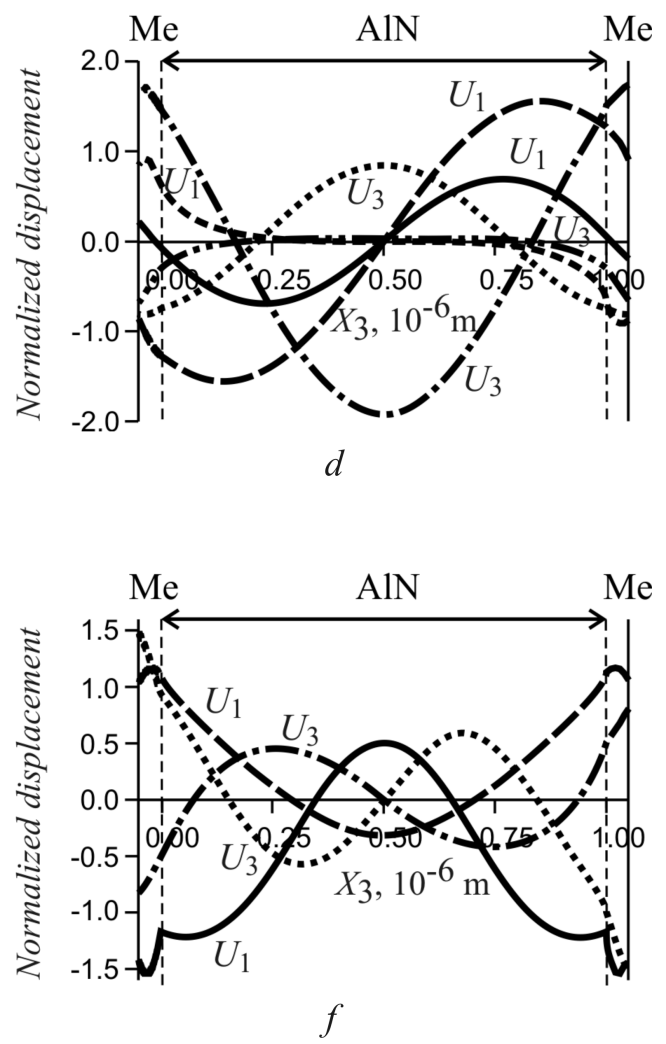

Fig. 3. The profiles of components of elastic displacements vectors $U_{1}$ and $U_{3}$ for Lamb wave modes in the maxima of $S$ curves for "Me/ZnO/Me" and "Me/AlN/Me" layered structures: $a-b-S_{0}$ mode; $c-d-A_{1}$ mode, $e-f-S_{1}$ mode. The thickness of metal and piezoelectric ratio $d / h=0.05$

\section{Conclusion}

The sensitivity $S$ of the elastic wave dispersive modes in the piezoelectric layered structures "Me/ZnO/Me" and "Me/AlN/Me" depends on the ratio of metal layer and piezoelectric material acoustic impedance, as well as the $d / h$ ratio and the $u$ parameter.

Note that the maximum values of sensitivity $S$ for elastic wave modes with large thicknesses of both metal layers (5\% and $10 \%$ thickness of the piezoelectric plate) are reached with 
"Al/AlN/Al" layered system configuration, i.e. in the system with low acoustic impedances for bulk longitudinal wave for materials of the metal and piezoelectric layers, which was shown earlier in [14]. However, when plating with thin layers, the maximum sensitivity $S$ values, in particular, for $S_{0}$ modes of the elastic Lamb wave, are reached both "Pt/ZnO/Pt" and "Pt/AlN/Pt" configuration of layered system, i.e. in systems with the most different acoustic impedances of layers and piezoelectric materials.

The study of component profiles of the elastic displacement vector of the elastic Lamb wave modes in local maxima of sensitivity curves $S$ in "Me/ZnO/Me" and "Me/AlN/Me" structures confirmed the above results about the metals with different acoustic impedances influence on amplitude and attenuation of elastic vibrations in layered structures. It is noted that minimal differences in the profiles of the displacement vectors are reached for systems with low values of acoustic impedances the materials of all layers. The maximum differences in these profiles are reached for systems with the most different acoustic impedance values.

It is noted that with an increase in the mode number of the elastic wave, the maximum and minimum of the sensitivity curve $S$ shift to the region of large values of the parameter $u$, which explains the increase of the recorded differences in the profiles of elastic waves.

The results obtained by computer simulation can be useful in the development of the acoustoelectronic devices based on Lamb and $S H$-waves.

\section{References}

[1] Q.Xie, S.Mezil, P.H.Otsuka et. al., Imaging Gigahertz Zero-Group-Velocity Lamb Waves, arXiv:1901.01013 [physics.app-ph].

[2] V.Yantchev, I.Katardjiev, Thin film Lamb wave resonators in frequency control and sensing applications: a review, Journal of Micromechanics and Microengineering, 23(2013), 043001 (14).

[3] T.Nakamoto, T.Moriizumi,A theory of a Quartz Crystal Microbalance Based Upon a Mason Equivalent Circuit, Japanese Journal of Applied Physics, Part 1 (Regular Papers \& Short Notes), 29(1990), 963-969.

[4] B.P.Sorokin, G.M.Kvashnin, A.V.Telichko, A.S.Novoselov, S.I.Burkov, Lamb Waves Dispersion Curves for Diamond Based Piezoelectric Layered Structure, Applied Physics Letters, 108(2016), no. 5, 113501.

[5] G.D.Mansfeld, S.G.Alekseev, I.M.Kotelyansky, Acoustic HBAR Spectroscopy of Metal (W, Ti, Mo, Al) Thin Films, Proc. Ultras. Symp., IEEE, 2001, 415-418.

[6] Z.Zhang, Z.Wen, C.Wang, Investigation of Surface Acoustic Waves Propagating in ZnO$\mathrm{SiO}_{2}-\mathrm{Si}$ Multilayer Structure, Ultrasonics, 53(2013), no. 2, 363-368.

[7] K.Tsubouchi, K.Sugai, N.Mikoshiba, AlN material constants evaluation and SAW properties on $\mathrm{AlN} / \mathrm{Al}_{2} \mathrm{O}_{3}$ and $\mathrm{AlN} / \mathrm{Si}$, Proc. IEEE Ultrason. Symp. Chicago, USA, 1981, 375-380.

[8] R.E.Macfarlane, J.A.Rayne, C.K.Jones, Anomalous temperature dependence of shear modulus C44 for platinum, Physics Letters, 18(1965), no. 2, 91-92.

[9] G.W.Farnell, Acoustic Surface Waves Topics in Applied Physics. Ed. by A. A. Oliner, 1978. 
[10] B.P.Sorokin, G.M.Kvashnin, A.V.Telichko, S.I.Burkov, V.D.Blank, Piezoelectric-Layered Structures Based on Synthetic Diamond, InTech: Piezoelectric Materials, Ed. Toshio Ogawa (2016), 161-199.

[11] S.I.Burkov, O.P.Zolotova, B.P.Sorokin, Analysis of the metal layer thickness influence on the dispersion characteristics of acoustic waves propagating in the layered piezoelectric structure "Me/AlN/Me/diamond", Ultrasonics, 83(2018), 188-193.

[12] I.E.Kuznetsova, B.D.Zaitsev, S.G.Joshi, A.S.Kuznetsova, Gravimetric Sensitivity of Acoustic Waves in Thin Piezoelectric Plates in the Presence of Liquids, Techn. Phys. Lett., 32(2006), 729-731.

[13] S.I.Burkov, O.P.Zolotova, B.P.Sorokin, P.P.Turchin, V.S.Talismanov, Features of acoustic wave propagation in the $\mathrm{Me} / \mathrm{ZnO} / \mathrm{Me} /$ diamond waveguide structure, The Journal of the Acoustical Society of America, 143(2018), 16-22.

[14] O.P.Zolotova, S.I.Burkov, Simulation of metal layers thickness influence on phase velocities of acoustic waves in the piezoelectric plates, Siberian Journal of Science and Technology, 19(2018), 396-404.

\title{
Особенности влияния металлизации на фазовые скорости акустических волн в пьезоэлектрических пластинах
}

Ольга П. Золотова

НОЦ «Институт космических исследований и высоких технологий». Сибирский государственный университет науки и технологий им. М. Ф. Решетнева Красноярский рабочий, 31, Красноярск, 660037

Россия

Сергей И. Бурков

Институт инженерной физики и радиоэлектроники Сибирский федеральный университет Свободный, 79, Красноярск, 660041

Россия

\begin{abstract}
В работе выполнен анализ влияния нагрузки в виде двух металлических слоев на изменение фазовой скорости дисперсионных мод упругой волны Лэмба и $S H$-волны в структурах вида "Me/ZnO/Me"u "Me/AlN/Me"в зависимости от частоты упругой волны и отношения толщин слоев металла и пьезоэлектрика. В качестве материалов металлического слоя (Ме) использовали алюминий (Al), молибден (Mo) и платину (Pt). Только моды упругой волны Лэмба обладают локализованными максимумами чувствительности $S$ для всех типов структур. Системы с низкими значениями акустических импедансов материалов слоев и пластин обладают максимальными значениями $S$ при металлизачии тонкими слоями, а также имеют минимальные отличия профилей компонент векторов смещений упругой волны. Системы с максималъно различными значениями акустических импедансов материалов слоев и пластин обладают максимальными значениями $S$ при металлизации толстыми слоями, а такюе имеют максимальные отличия профилей компонент векторов смещений упругой волны.
\end{abstract}

Ключевые слова: пъезоэлектрическая пластина, волна Лэмба, SH-волна, массовая нагрузка, компъютерное моделирование 